\title{
Evaluation the intestinal level of LCN2/NGAL in patients with Clostridium difficile infection in the south of Iran
}

\author{
Seyedeh Mahsan Hoseini-Alfatemi ${ }^{1}$, Hadi Sedigh Ebrahim-Saraie ${ }^{2,}$ \\ ${ }^{1}$ Pediatric Infections Research Center, Research Institute for Children's Health, Shahid Beheshti University of Medical Sciences, Tehran, \\ Iran \\ ${ }^{2}$ Razi Clinical Research Development Unit, Razi Hospital, Guilan University of Medical Sciences, Rasht, Iran
}

\begin{abstract}
Clostridium difficile is a Gram-positive obligate anaerobic bacterium that recognized an important pathogen of humans. The present study aimed to evaluate the intestinal level of neutrophil gelatinaseassociated lipocalin (NGAL) in patients with $C$. difficile infection (CDI) as a disease activity marker in the south of Iran. This cross-sectional study conducted from October 2017 to June 2018 on patients referred to Nemazee and Amir Hospital in Shiraz, South of Iran. Patients less than two years old were excluded from the study. The study population was consist of 46 cases (Symptomatic patients that confirmed as a CDI), and 21 control individuals (Asymptomatic patients colonized by $C$. difficile). $C$. difficile isolates were identified by conventional microbiological producers and amplification of housekeeping gene by PCR method. The level of NGAL was determined by enzyme-linked immunosorbent assay (ELISA) according to the instructions of the kit manufacturer. The results showed that the level of NGAL in symptomatic patients' (case group) was higher than asymptomatic carriers (control group), $5.9 \mathrm{ng} / \mathrm{mL}$ vs. $4.1 \mathrm{ng} / \mathrm{mL}$; however the observed difference was not statistically significant. Also, in both groups, the mean level of NGAL was significantly higher in patients with gastrointestinal diseases than others. In summary, despite all the limitations, the results of the present study indicate that the intestinal level of NGAL is a biological indicator of intestinal inflammation, regardless of CDI. However, further study needs to elucidate the role of NGAL in inflammation caused by bacterial infections.
\end{abstract}

Keywords: Clostridium difficile; CDI; Lipocalin-2; NGAL; Gastrointestinal diseases

\section{Introduction}

Clostridium difficile is a Gram-positive obligate anaerobic bacterium that recognized an important pathogen of humans. The organism can cause serious diseases such as pseudomembranous colitis (PMC), toxic megacolon, and perforation of the colon $[1,2]$. $C$. difficile is responsible for the majority of cases of nosocomial diarrhea [3]. Due to spore production,

\section{Corresponding author:}

Dr. Hadi Sedigh Ebrahim-Saraie, Ph.D

Razi Clinical Research Development Unit, Razi Hospital,

Guilan University of Medical Sciences, Rasht, Iran

Tel/Fax: +98 1333542460

Email: seddigh.hadi@gmail.com, seddigh.hadi@gums.ac.ir https://orcid.org/oooo-0001-8339-5199

Received: August, 03, 2020

Accepted: August, 15, 2020 they are often highly resistant to sterilizations and disinfectants which become them a successful healthcare-associated pathogen [4].

Neutrophil gelatinase-associated lipocalin (NGAL) also known as Lipocalin-2 (LCN2) belongs to a family of small secretory proteins that are expressed by different types of cells, the richest source of which is neutrophils $[5,6]$. The results of experiments show a 
systematic increase in the expression level of LCN2 in various models of colitis, including human inflammatory bowel diseases (IBD) [7]. Besides, human lipocalin has been reported to be increased in patients with ulcerative colitis [7]. Recently, it has been shown that LCN2 is a real-time indicator for kidney disease and meets all the criteria required for a biomarker [8]. Expression of LCN2 in adipose tissue has been increased in various experimental models of obesity and obese individuals, indicating that $\mathrm{LCN} 2$ may be involved in inflammatory disorders [7]. Chassaing et al. introduced the LCN2 in the stool as an indicator to identify inflammation caused by inflammatory bowel disease, which could be linked to various intestinal infections and used as a biomarker index $[7,9]$.

The present study aimed to evaluate the intestinal level of NGAL in patients with $C$. difficile infection (CDI) as a disease activity marker in the south of Iran.

\section{Materials and Methods}

\subsection{Study design}

This cross-sectional study conducted from October 2017 to June 2018 on patients referred to Nemazee and Amir Hospital in Shiraz, South of Iran. Patients less than two years old were excluded from the study. The study population was consist of 46 cases (Symptomatic patients that confirmed as a CDI), and 21 control individuals (Asymptomatic patients colonized by $C$. difficile). C. difficile were identified by conventional microbiological producers including characteristics on cycloserine-cefoxitin fructose agar (CCFA) (MAST Diagnostic, UK) and amplification of triose phosphate isomerase (tpi) housekeeping gene by PCR method [10, 11]. This study was following the declaration of Helsinki and ethical permission was sought from the institutional Ethics Committee of Shiraz University of Medical Sciences (Approval No. IR.SUMS.REC.1396.S872).

\subsection{Measurement of NGAL level}

The level of NGAL was determined by enzymelinked immunosorbent assay (ELISA) according to the instructions of the Lipocalin-2/NGAL Human ELISA kit manufacturer with a detection limit of $0.02 \mathrm{ng} / \mathrm{mL}$ (BioVendor, Czech Republic). The samples were diluted to a ratio of 1:10 according to the kit protocol and previous studies in this field. After performing the ELISA test preparation steps, the Optical density of each well was read with an ELISA reader at a wavelength of $450 \mathrm{~nm}$ and the results were reported in $\mathrm{ng} / \mathrm{mL}$. The final result was calculated by multiplying the dilution coefficient at the concentration reported by the device.

\subsection{Statistical analysis}

The analysis was performed by using SPSS ${ }^{\mathrm{TM}}$ software, version 21.o (IBM Co., Armonk, NY, USA). The results are presented as descriptive statistics in terms of relative frequency. Values were expressed as the mean \pm standard deviation (continuous variables) or percentages of the group (categorical variables). The paired $t$-tests were used to compare means, and a $P$ value $<0.05$ was considered as statistically significant.

\section{Results}

Totally, 46 symptomatic cases consist of $52.2 \%$ males and $47.8 \%$ females with a mean age of $31.4 \pm 24.6$ year, and 21 asymptomatic controls consist of $52.4 \%$ males and $47.6 \%$ females with a mean age of 43.1 \pm 23.1 year were included. The distribution of underlying diseases are shown in Table 1.

The results showed that the level of LCN2 in symptomatic patients' (case group) was higher than asymptomatic carriers (control group), $5.9 \mathrm{ng} / \mathrm{mL}$ vs. $4.1 \mathrm{ng} / \mathrm{mL}$; however the observed difference was not statistically significant (Figure 1).

To determine the relationship between NGAL levels and gastrointestinal diseases, the mean level of NGAL in symptomatic patients with ulcerative colitis, gastroenteritis, colorectal cancer, and Crohn's was compared with the patients with non-gastrointestinal diseases. As shown in Figure 2, the mean level of NGAL was significantly higher in patients with gastrointestinal diseases than others $(12.6 \mathrm{ng} / \mathrm{mL}$ vs. $3.0 \mathrm{ng} / \mathrm{mL}$; P <0.001).

Also, in asymptomatic carriers (Figure 3), the mean level of NGAL was significantly higher in patients with gastrointestinal diseases than in others (8.1 ng/mLvs. 2.0 ng/mL; P <0.009).

\section{Discussion}

In recent years, the prevalence of CDI has increased significantly and has become a growing health concern, especially in hospitals [12]. Hospitalacquired CDI can be a consequence of the development of the disease due to colonization with $C$. difficile or exposure to a new strain transmitted from patients or the environment [13]. 


\section{Hoseini-Alfatemi et al.}

Table 1 . The distribution of underlying diseases among studied patients

\begin{tabular}{lcccc}
\hline \multirow{2}{*}{ Underlying disease } & \multicolumn{2}{c}{ Case (symptomatic) } & \multicolumn{2}{c}{ Control (asymptomatic) } \\
\cline { 2 - 5 } & Frequency & Percent & Frequency & Percent \\
\hline Ulcerative colitis (UC) & 8 & 17.4 & 1 & 4.8 \\
\hline Acute lymphoblastic leukemia (ALL) & 5 & 10.9 & 2 & 9.5 \\
\hline Liver transplantation & 5 & 10.9 & 3 & 14.3 \\
\hline Gastroenteritis & 5 & 10.9 & 4 & 19.0 \\
\hline Acute myeloid leukemia (AML) & 1 & 2.2 & - & - \\
\hline Kidney failure & 4 & 8.7 & 2 & 9.5 \\
\hline Diabetes mellitus (DM) & 2 & 4.3 & - & - \\
\hline Metabolic disorder & 2 & 4.3 & - & - \\
\hline Pneumonia & 2 & 4.3 & - & - \\
\hline Autoimmune hepatitis & 1 & 2.2 & - & - \\
\hline Chronic lymphocytic leukemia (CLL) & 1 & 2.2 & 1 & 4.8 \\
\hline Colon Cancer & 1 & 2.2 & - & - \\
\hline Crohn's & 1 & 2.2 & 1 & 4.8 \\
\hline Glaucoma & 1 & 2.2 & - & - \\
\hline Liver neoplasms & 1 & 2.2 & - & - \\
\hline Multiple myeloma & 1 & 2.2 & - & - \\
\hline Myelodysplastic syndromes (MDS) & 1 & 2.2 & & - \\
\hline Non-Hodgkin lymphoma (NHL) & 1 & 2.2 & - & - \\
\hline Optic Glioma & 1 & 2.2 & - & \\
\hline Osteosarcoma & 1 & 2.2 & - & - \\
\hline Wilm's Tumor & 1 & 2.2 & - & - \\
\hline Chronic myelogenous leukemia (CML) & - & - & 2 & 9.5 \\
\hline Aspiration pneumonia & - & - & 1 & 4.8 \\
\hline GI vasculitis & - & - & 1 & 4.8 \\
\hline Guillain-Barre & - & - & 1 & 4.8 \\
\hline Kidney transplantation & - & - & 1 & 4.8 \\
\hline Mushroom poisoning & - & - & 1 & 4.8 \\
\hline Total & 46 & 100 & 21 & 100 \\
\hline & & & &
\end{tabular}

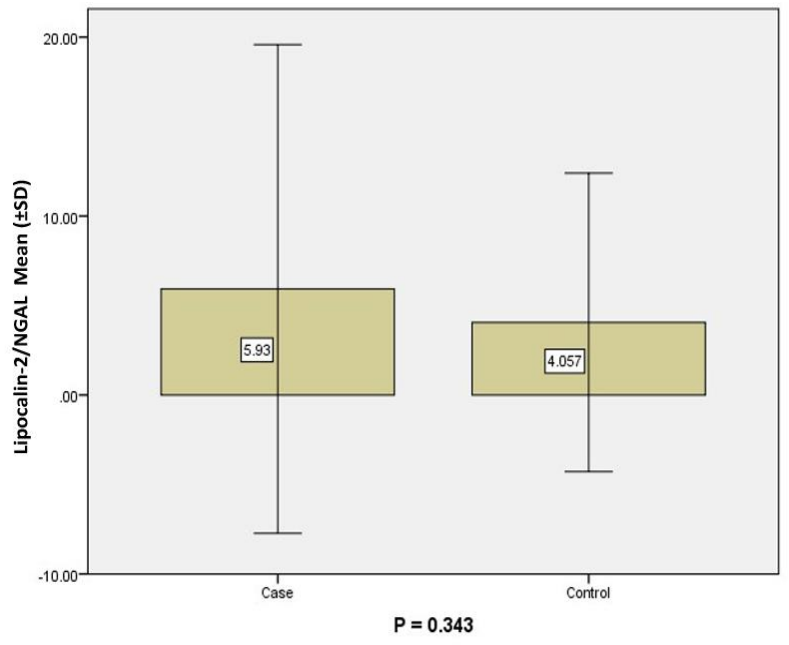

Figure 1. Comparison the intestinal level of NGAL in case (symptomatic) and control (asymptomatic carriers) groups

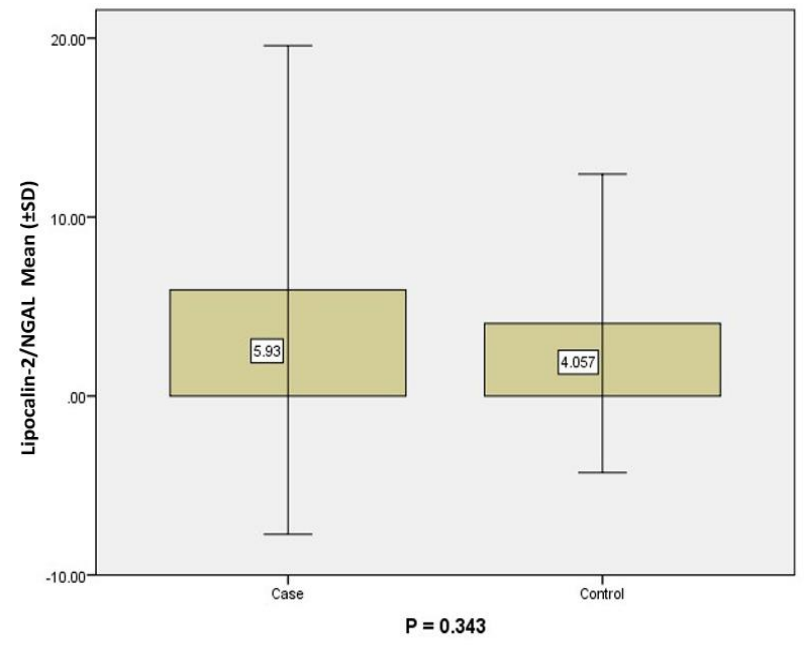

Figure 2: Comparison the intestinal level of NGAL in patients with gastrointestinal diseases and other patients among the case group (symptomatic) 


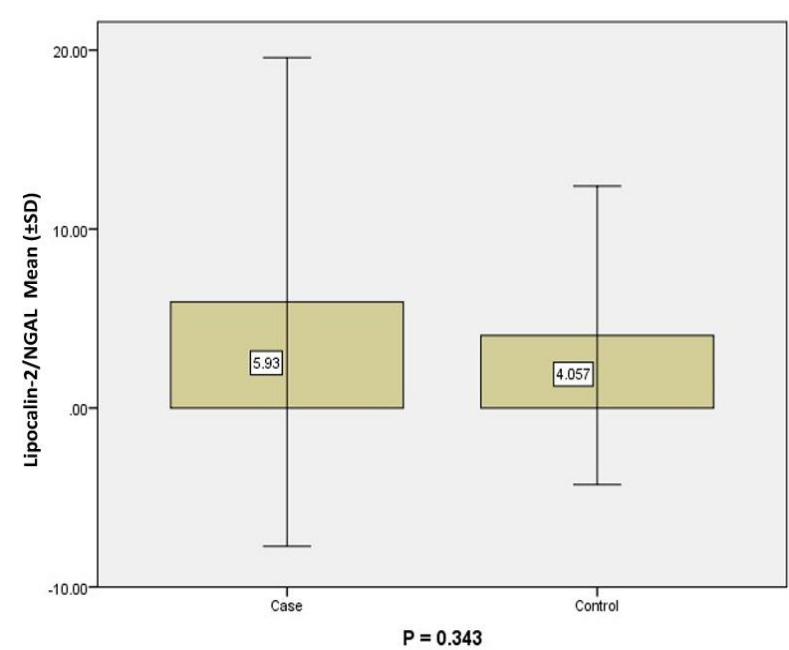

Figure 3. Comparison the intestinal level of NGAL in patients with gastrointestinal diseases and other patients among the control group (asymptomatic carriers)

In a study by Chassaing et al., suggested that the LCN2 in feces can be an indicator for the identification of inflammation caused by IBD in mouse models. Also, they suggest that LCN2 could be linked to other intestinal infections, but to introduce as a biomarker needs to future examination [7].

In the present study, there was no statistically significant difference between the levels of LCN2 among case and control groups. However, the intestinal level of $\mathrm{LCN} 2$ in both groups was significantly higher in people with gastrointestinal diseases. Previously, Xiu Guo et al. had shown that in infected animal models with pathogenic strains of Escherichia coli, the level of LCN2 in the jejunum increased rapidly [14]. These results indicate that LCN2 as a proinflammatory factor can be expressed independently of the presence of bacterial infection, but the presence of any intestinal inflammation can significantly promote its production. It has been suggested that alteration in the level of LCN2 can balance the level of the intestinal microbiome and the host response to infection [7, 15]. It has also been shown that increasing LCN2 levels helps to limit infection by inhibiting siderophore receptors and reducing pathogen access to iron [14].

The main limitations including the fact that the present study is a cross-sectional study that was performed only on patients with antibiotic-related diarrhea and not all diarrhea patients were tested for the presence of $C$. difficile.
In summary, despite all the limitations, the results of the present study indicate that the intestinal level of NGAL is a biological indicator of intestinal inflammation, regardless of CDI. However, further study need to elucidate the role of NGAL in inflammation caused by bacterial infections.

\section{Author Contributions}

Conception or design of the work: HS; Data collection: HS; Data analysis and interpretation: $\mathrm{MH}$, HS; Drafting the article: MH, HS; Critical revision of the article: MH, HS. All authors read and approved the final version of manuscript.

\section{Conflict of Interests}

The authors declare that they have no conflicts of interest.

\section{Ethical declarations}

The study design approved by the local Ethics Committee of Shiraz University of Medical Sciences (Approval No. IR.SUMS.REC.1396.S872).

\section{Financial Support}

This study was supported by Shiraz University of Medical Sciences with grant No. 96-14947.

\section{References}

1. Edwards AN, Suárez JM, McBride SM. Culturing and maintaining Clostridium difficile in an anaerobic environment. $\mathrm{J}$ Vis Exp. 2013; (79):e50787.

2. Curry S. Clostridium difficile. Clin Lab Med. 2010; 30(1):329-42. 3. Karaaslan A, Soysal A, Yakut N, Akkoç G, Demir SO, Atıcı S, et al. Hospital acquired Clostridium difficile infection in pediatric wards: a retrospective case-control study. Springerplus. 2016; 5(1):1329.

4. Lawson PA, Citron DM, Tyrrell KL, Finegold SM. Reclassification of Clostridium difficile as Clostridioides difficile (Hall and O'Toole 1935) Prévot 1938. Anaerobe. 2016; 40:95-9. 5. Kjeldsen L, Cowland JB, Borregaard N. Human neutrophil gelatinase-associated lipocalin and homologous proteins in rat and mouse. Biochim Biophys Acta Protein Struct Molec Enzym. 2000; 1482(1):272-83.

6. Chakraborty S, Kaur S, Guha S, Batra SK. The multifaceted roles of neutrophil gelatinase associated lipocalin (NGAL) in inflammation and cancer. Biochim Biophys Acta. 2012; 1826(1):129-69.

7. Chassaing B, Srinivasan G, Delgado MA, Young AN, Gewirtz AT, Vijay-Kumar M. Fecal lipocalin 2, a sensitive and broadly dynamic non-invasive biomarker for intestinal inflammation. PLoS One. 2012; 7(9):e44328.

8. Bolignano D, Donato V, Coppolino G, Campo S, Buemi A, Lacquaniti A, et al. Neutrophil gelatinase-associated lipocalin (NGAL) as a marker of kidney damage. Am J Kidney Dis. 2008; 52(3):595-605.

9. Deis JA, Guo H, Wu Y, Liu C, Bernlohr DA, Chen X. Adipose Lipocalin 2 overexpression protects against age-related decline in 


\section{Hoseini-Alfatemi et al.}

thermogenic function of adipose tissue and metabolic deterioration. Mol Metab. 2019; 24:18-29.

10. Lemee L, Dhalluin A, Testelin S, Mattrat MA, Maillard K, Lemeland JF, et al. Multiplex PCR targeting tpi (triose phosphate isomerase), tcdA (Toxin A), and tcdB (Toxin B) genes for toxigenic culture of Clostridium difficile. J Clin Microbiol. 2004; 42(12):5710-4.

11. Sedigh Ebrahim-Saraie H, Heidari H, Amanati A, Bazargani A, Alireza Taghavi S, Nikokar I, et al. A multicenter-based study on epidemiology, antibiotic susceptibility and risk factors of toxigenic Clostridium difficile in hospitalized patients in southwestern Iran. Infez Med. 2018; 26(4):308-15.

12. Depestel DD, Aronoff DM. Epidemiology of Clostridium difficile infection. J Pharm Pract. 2013; 26(5):464-75.
13. Furuya-Kanamori L, Marquess J, Yakob L, Riley TV, Paterson DL, Foster NF, et al. Asymptomatic Clostridium difficile colonization: epidemiology and clinical implications. BMC Infect Dis. 2015; 15:516.

14. Guo BX, Wang QQ, Li JH, Gan ZS, Zhang XF, Wang YZ, et al. Lipocalin 2 regulates intestine bacterial survival by interplaying with siderophore in a weaned piglet model of Escherichia coli infection. Oncotarget. 2017; 8(39):65386-96.

15. Singh V, Yeoh BS, Chassaing B, Zhang B, Saha P, Xiao X, et al. Microbiota-inducible Innate Immune, Siderophore Binding Protein Lipocalin 2 is Critical for Intestinal Homeostasis. Cell Mol Gastroenterol Hepatol. 2016; 2(4):482-98.e6. 